Clapp NK, Henke ML, Lushbaugh CC, Humason GL, Gangaware BL (1988) Effect of various biological factors on spontaneous marmoset and tamarin colitis: a retrospective histopathologic study. Dig Dis Sci 33:1013-1019

Jonas AM, Tomita Y, Wyand S (1965) Enzootic intestinal adenocarcinoma in hamsters. J Am Vet Med Assoc 147:1102-1108

Kennedy PC, Cello RM (1966) Colitis in boxer dogs. Gastroenterology 51:926-931

Kirkwood JK, Pearson GR, Epstein MA (1986) Adenocarcinoma of the large bowel and colitis in captive cottontop tamarins, Saguinus o. oedipus. J Comp Pathol 96:507-515

Lushbaugh C, Humason G, Clapp N (1985) Histology of colitis: Saguinus oedipus oedipus and other marmosets. Dig Dis Sci 30:45S-51S

Madara JL, Podolsky DK, King NW, Sehgal PK, Moore R, Winter HS (1985) Characterization of spontaneous colitis in cotton-top tamarins (Saguinus oedipus) and its response to sulfasalazine. Gastroenterology 88:13-19

Moore R (1985) Nonviral infectious agents and marmoset (Saguinus oedipus) colitis. Dig Dis Sci 30:69S-71S

Moore R, King N, Alroy J (1988a) Characterization of colonic cellular glycoconjugates in colitis and cancerprone tamarins versus colitis and cancer-resistant primates. Am J Pathol 131:477-483

Moore R, King N, Alroy J (1988b) Differences in cellular glycoconjugates of quiescent, inflamed, and neoplastic colonic epithelium in colitis and cancer-prone tamarins Am J Pathol 131:484-489

Nair PP, Shami S, Johnson JA, Ausman LM (1990) Fecal mutagen load in cancer-prone cotton-top tamarins Saguinus oedipus) fed high and low fat diets. FASEB J IV:A1176
Onderdonk AB (1985) Experimental models for ulcerative colitis. Dig Dis Sci 30:40S-44S

Podolsky DK, Madara JL, King NW, Sehgal P, Moore R, Winter HS (1985) Colonic mucin composition in primates. Selective alterations associated with spontaneous colitis in the cotton-top tamarin. Gastroenterology 88:20-25

Richter CB, Lushbaugh CC, Swartzendruber DC (1980) Cancer of the colon in cotton-topped tamarins. In: Montali RJ, Migaki G (eds) The comparative pathology of zoo animals. Smithsonian Institution Press, Washington DC, pp 567-571

Russell RG, Brian DA, Lenhard A, Potgiueter LND, Gillespie D, Clapp NK (1985) Coronavirus-like particles and campylobacter in marmosets with diarrhea and colitis. Dig Dis Sci 30:72S-77S

Scott GBD, Keymer IF (1975) Ulcerative colitis in apes: a comparison with the human disease. JPathol 115:241-244

Snook SS, Canfield DR, Sehgal PK, King NW (1989) Focal ulcerative ileocolitis with terminal thrombocytopenic purpura in juvenile cotton top tamarins (Saguinus oedipus). Lab Anim Sci 39:109-114

Stout C, Snyder RL (1969) Ulcerative colitis-like lesion in Siamang gibbons. Gastroenterology 57:256-261

Strandle A, Sommers SC, Petrak M (1954) Regional enterocolitis in cocker spaniel dogs. Arch Pathol 57:3457

Strober W (1985) Animal models of inflammatory bowel disease - an overview. Dig Dis Sci 30:3S-10S

Van Kruiningen HJ (1967) Granulomatous colitis of boxer dogs: comparative aspects. Gastroenterology 53:114-122

Watt J, Marcus R (1971) Carrageenan-induced ulceration of the intestine in the guinea pig. Gut 12:164-171

Wood JD, Peck OC, Sharma HM, Mekhjian HS, Stone DW, Stonerook M, Weiss HS, Hernandez-CJ, RodriquezM JV, Rodriquez-M MA (1990) Captivity promotes colitis in the cotton-top tamarin (Saguinus oedipus). Gastroenterology 98:A480

\title{
Chronic Colitis, Juvenile Macaca mulatta
}

\author{
Rick R. Adler, Peter F. Moore, Douglas L. Schmucker, and Linda J. Lowenstine
}

Synonyms. Inflammatory bowel disease; chronic colitis.

\section{Gross Appearance}

The general body condition of affected animals reflects emaciation and dehydration. These animals have a moderately dilated colon filled with brown or green fluid feces. The colonic mucosa is diffusely thickened and granular (Fig. 90). Areas of the colonic mucosa may have a rugose appearance and small erosions or microulcers may be evident. Mesenteric lymph nodes are frequently enlarged. Thymic atrophy and splenomegaly may be found in some animals. Gross lesions are not seen in other organs.

\section{Microscopic Features}

The entire large intestine is involved by diffuse chronic inflammation, usually confined to the mucosa. Histologic changes are characterized by prominent lymphocytic and plasmacytic infiltration of the lamina propria, particularly in the deeper portions of the mucosa between crypts (Fig. 91). Macrophages and neutrophils may be scattered throughout the lamina propria. Acute inflammation of mucosal crypts (neutrophilic infiltration, crypt abscesses, and crypt ulceration) is common in the cecum and proximal colon (Fig. 92). Crypt abscesses are less common in the rectum and thus may be absent in biopsy specimens obtained from sigmoidoscopy. The mucosa is mea- 


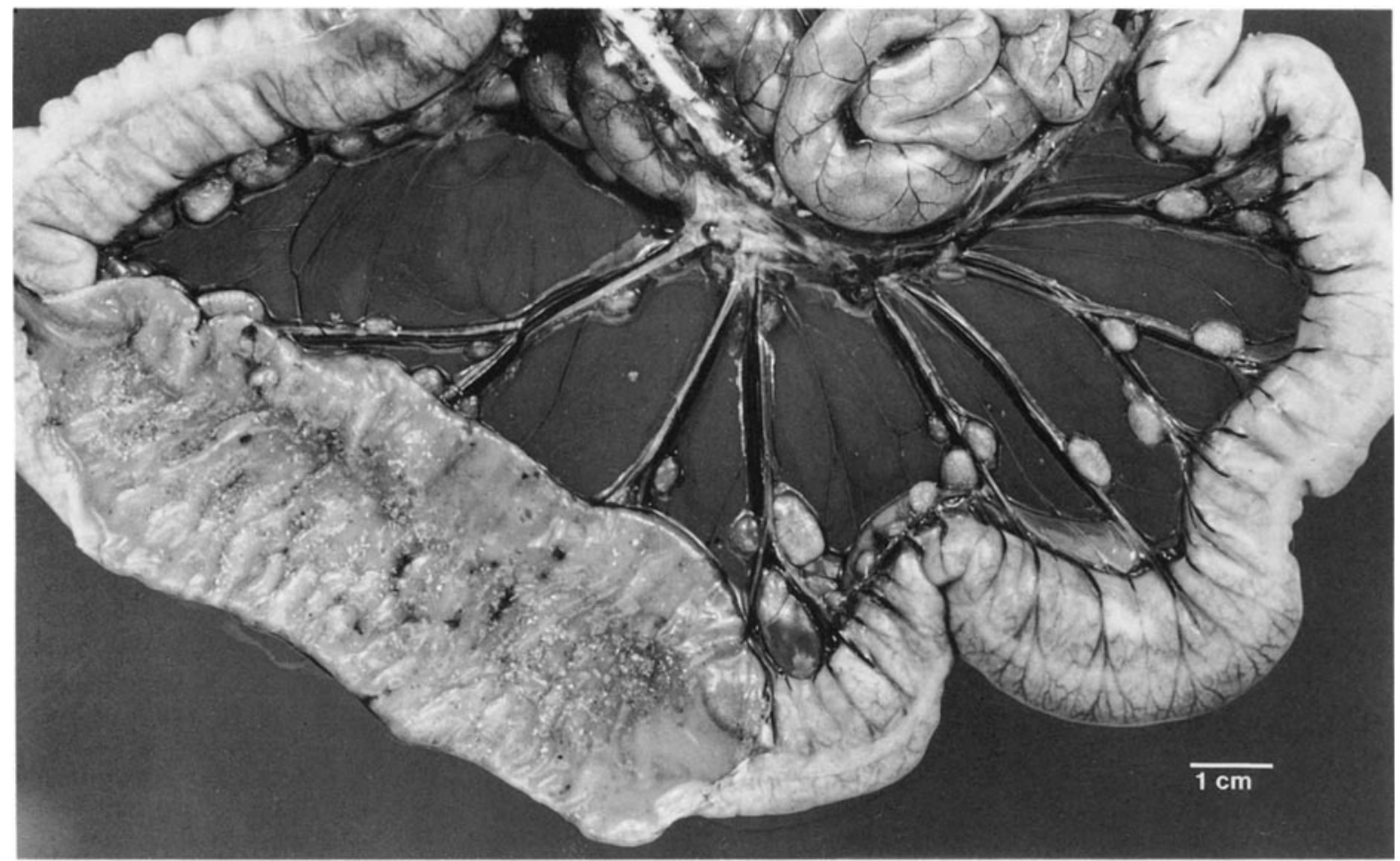

Fig. 90. Colon and small intestine (top, center) from a juvenile rhesus macaque with chronic colitis. The proximal and midportions of the colon have been opened to show the thickened, rugose and granular appearance of the mucosa. There are a few areas of mucosal erosion and hemorrhage. Note the enlargement of colonic lymph nodes and complete absence of adipose tissue in the mesentery. Bar, $1 \mathrm{~cm}$ surably thickened and hyperplastic. Mucosal gland architecture may be distorted by tortuous, cribiform, or bifurcated crypts. Crypt epithelial changes include karyomegaly, hyperchromicity, pseudostratification, frequent mitotic figures, and the presence of mitoses in mid- to upper portions of the mucosal glands. Goblet cell depletion and surface enterocyte alterations are common. The latter include cellular tufts, micro-erosions, attenuation, irregular cell size and shape, disparity of nuclear size, and hyperchromicity.

Mucosal microhernias (Fig. 93) into submucosal lymphoid nodules are present in about half of all colon samples from necropsy, and are most frequent in the proximal colon. Approximately half of all cases have chronic inflammation of the terminal ileum, which is characterized by lymphocytic and plasmacytic infiltration of the lamina propria, villus blunting, goblet cell depletion, and crypt hyperplasia.

Histologic lesions observed in other tissues may include lymphoid hyperplasia in mesenteric nodes, chronic superficial gastritis, chronic cholecystitis, mild periportal hepatitis, and thymic atrophy.

\section{Differential Diagnosis}

It is important to differentiate between acute and chronic diarrhea and colitis because these manifestations usually reflect disparate causes. Whereas a variety of infectious bacteria, protozoa, and viruses have been associated with acute diarrhea in both human and nonhuman primates, in humans, infectious causes for chronic diarrhea are considered unlikely (Smalley et al. 1982). Acute self-limiting colitis, the inflammatory pattern associated with infectious agents such as Campylobacter and Shigella (Kumar et al. 1982; Nostrant et al. 1987), can be distinguished histologically from chronic colitis of juvenile rhesus macaques and chronic idiopathic inflammatory bowel disease of humans. Acute self-limiting colitis differs from chronic colitis and inflammatory bowel disease by the paucity of mononuclear inflammatory cells in the lamina propria, absence of mucosal thickening, hyperplasia, and gland distortion. Crypt abscesses, surface epithelial damage, and goblet cell depletion can be found in both chronic and acute self-limiting colitis. Food hypersensi- 


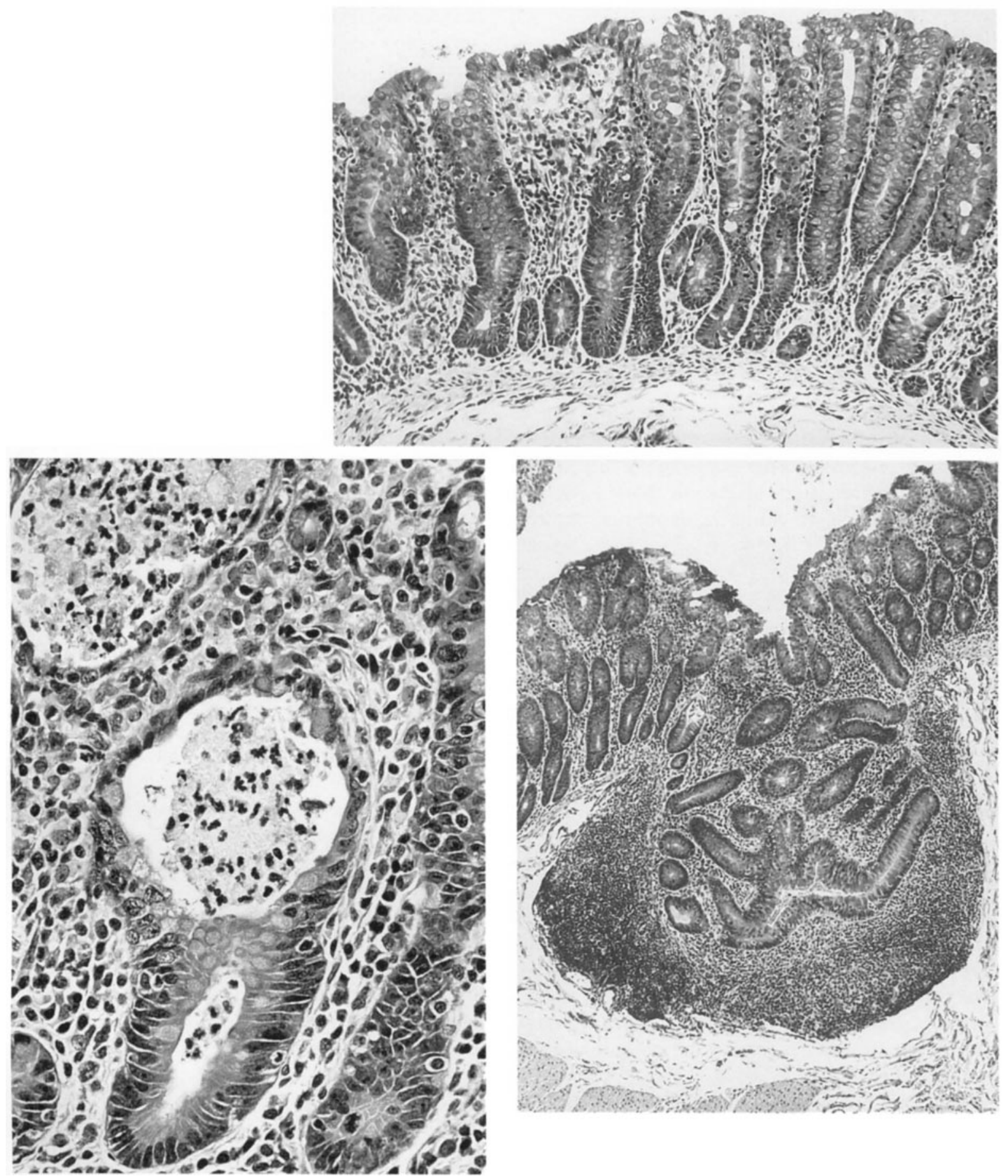

Fig. 91 (above). Proximal colon from a juvenile rhesus macaque with chronic colitis. The lamina propria has a moderately dense mononuclear inflammatory cell infiltration and the mucosal glands are irregular and tortuous. Mucosal crypts have a hyperplastic appearance and mitotic figures are frequent and evident at the mid- to upper portions of the mucosa. Goblet cell number is reduced and surface epithelial cells lack uniformity. Note single crypt abscess (arrow). $\mathrm{H}$ and $\mathrm{E}, \times 45$
Fig. 92 (lower left). Crypt abscess within a colonic mucosal gland of a juvenile rhesus macaque with chronic colitis. The gland is dilated, the epithelium is irregular and attenuated, and the lumen contains neutrophils and inflammatory debris. The lamina propria contains a dense inflammatory cell infiltration consisting of lymphocytes, plasma cells and macrophages. $\mathrm{H}$ and $\mathrm{E}, \times 100$

Fig. 93 (lower right). Mucosal "microhernia" in the proximal colon of a juvenile rhesus macaque with chronic colitis. The mucosa is herniated into the underlying submucosal lymphoid nodule. $\mathrm{H}$ and $\mathrm{E}, \times 20$ 
tivity should be included in the differential diagnoses when there is evidence of malabsorption. Sensitization to dietary components may also represent a contributory component in the pathogenesis of chronic colitis.

Chronic colitis in juvenile rhesus macaques must be distinguished from chronic diarrhea in nonhuman primates associated with simian acquired immunodeficiency syndrome. Asian macaques experimentally or naturally infected with either simian immunodeficiency virus or type D retrovirus may develop chronic diarrhea associated with opportunistic infections, immunocompromise, or other unknown factors (Baskin et al. 1988; Lackner et al. 1990).

A similar pattern of chronic inflammation can be seen in adult macaques and other species of nonhuman primates. In older animals, the differential diagnosis for recurrent or chronic diarrhea should include intestinal amyloidosis, neoplasia, and colonic fibrosis or stricture formation. These lesions may possibly represent long-term sequelae of chronic inflammation.

Recurrent diarrhea, not necessarily associated with chronic inflammation, may be attributable to pancreatic insufficiency, malabsorption, secretory mechanisms, or disturbances of motility.

\section{Biologic Features}

Rhesus macaques identified most often with chronic colitis are generally between 10 months and 3 years of age and have been weaned from their mother through a nursery program. Approximately $8 \%-10 \%$ of this group in an affected colony will eventually develop chronic colitis. Diseased animals have growth retardation or weight loss and recurrent episodes of diarrhea often beginning during infancy. Typically, these individuals fail to respond to antimicrobial therapy in contrast to most of their peers.

The definitive etiology of chronic colitis and diarrhea in juvenile rhesus macaques is unidentified. Campylobacter and various intestinal protozoa can be identified in the stool of these animals throughout the course of the disease. Shigella, Yersinia, or Salmonella are rarely isolated. The causative role of these agents in chronic diarrhea is uncertain, and in about half of the episodes of diarrhea no pathogen can be found. Campylobacter has been isolated from both normal and diarrheic juvenile rhesus macaques with similar frequency (Fox 1982; Russell et al. 1987) and a carrier state for Campylobacter in nonhuman pri- mates is recognized (Ackerman et al. 1982). Nonpathogenic strains of $C$. jejuni have been identified in human isolates and different serotypes and biotypes of this organism have been described in a variety of hosts (Fox 1982; Walker et al. 1986). Virulence factors for Campylobacter have not been characterized for nonhuman primate isolates. Similarly, nonvirulent strains of intestinal protozoa are common (Burrows 1972; Shadduck and Pakes 1978; Toft 1982). Mechanisms of diarrheal disease other than intestinal infection and inflammation are also under investigation.

\section{Pathogenesis}

The current and most widely accepted concept in human patients of the pathogenesis of chronic idiopathic intestinal inflammation such as inflammatory bowel disease (ulcerative colitis, Crohn's disease) suggests that these spontaneous conditions are the net result of immunologically mediated inflammation in individuals who may be genetically or otherwise predisposed to an exaggerated or improperly regulated intestinal immune response to an unknown antigen or antigens (MacDermott and Stenson 1988; Shorter and Kirsner 1985). In humans, the search for the unknown initiating antigen(s) has been intense and proposed factors encompass a long list of bacteria and viruses, as well as extrinsic nonmicrobial antigens such as food allergens. The nature of the antigen(s) remains a highly controversial topic and none of the microorganisms or proposed dietary components can be given definitive regard as to their etiologic significance (Dayal and DeLellis 1989; Shorter and Kirsner 1985). It is conceivable that more than one agent or antigen could initiate the intestinal inflammatory response which results in inflammatory bowel disease.

Although the initiating events are currently unknown, the mechanisms of the immediate causes of morphologic and functional alterations seen in chronic colitis are emerging. Soluble mediators of inflammation associated with edema and hyperemia, neutrophil and macrophage infiltration, and immune activation and modulation have been identified in inflammatory bowel disease, experimental models of colitis (Lauritsen et al. 1985; Ligumsky et al. 1988; Matsumoto et al. 1988; Sharon et al. 1978; Sharon and Stenson 1984; Stenson 1986; Vilaseca et al. 1990), and in juvenile rhesus macaques with chronic colitis (Adler et al. 1990). These mediators, rather than any particu- 
Table 7. Comparisons of the relative frequency of pathologic findings in chronic colitis of juvenile rhesus macaques and ulcerative colitis and Crohn's disease of humans

\begin{tabular}{llll}
\hline & JRM & UC & CD \\
\hline Gross features & & & \\
Total colonic involvement & +++ & +++ & + \\
Ileum involvement & ++ & ++ & +++ \\
Rectal involvement & +++ & +++ & + \\
Thickening of intestine & +++ & +++ & +++ \\
Ulceration and erosion & + & +++ & + \\
Segmental lesions & 0 & 0 & +++ \\
Microscopic features & & & \\
Lymphocytic-plasmacytic infiltration & +++ & +++ & ++ \\
Crypt abscesses & +++ & +++ & + \\
Goblet cell depletion & +++ & ++ & + \\
Crypt hyperplasia/dysplasia & ++ & +++ & + \\
Submucosal involvement & ++ & + & +++ \\
Transmural involvement & 0 & + & +++ \\
Granulomas & 0 & 0 & ++ \\
\hline
\end{tabular}

JRM, chronic colitis, juvenile rhesus macaques; UC, ulcerative colitis, humans; $\mathrm{CD}$, Crohn's disease, humans.

Modified from Glickman 1987.

lar etiologic agent, are most likely the common mechanisms that explain the similar clinical and histologic manifestations shared by chronic colitis in its various forms (MacDermott and Stenson 1988).

In juvenile rhesus macaques, the etiology and pathogenesis of chronic colitis are probably multifactorial. Intestinal infection and reinfection, stresses associated with captivity or disease, malnutrition associated with multiple episodes of diarrhea and anorexia, diminished mucosal defenses, and hypersensitivity resulting from early neonatal exposure to antigenic dietary components may combine to initiate or perpetuate a sequence that eventuates in chronic intestinal inflammation.

\section{Comparison with Other Species}

The lesions of the large intestine in this group of juvenile rhesus macaques are similar to many of the alterations seen in humans with inflammatory bowel disease, particularly ulcerative colitis (Table 7). Ulcerative colitis is characterized by uniform and continuous chronic inflammation of the colonic mucosa with a high frequency of rectal involvement. In contrast, Crohn's disease is often manifest by segmental involvement (skip lesions) and granuloma formation involving the ileum and, less frequently, colon and rectum. In ulcerative colitis, the terminal ileum may also be involved, secondary to proximal colonic involvement, a phenomenon referred to as "backwash ileitis" (Dayal and DeLellis 1989; Glickman 1987). Key histologic features, similar in both ulcerative and chronic colitis of juvenile rhesus macaques, include mucus depletion, diffuse plasma cell infiltration of lamina propria, and alteration of crypt architecture. Mucosal microherniation, first described in ulcerative colitis in humans (Dyson 1975), is also a prevalent feature of chronic colitis of juvenile rhesus macaques.

In contrast to ulcerative colitis of humans, severe ulceration and frank bloody stool are not typical features of chronic colitis in juvenile rhesus macaques. Dysplastic changes in the mucosal crypts, common in recurrent cases of ulcerative colitis and considered a preneoplastic condition, are occasionally seen in juvenile rhesus macaques with chronic colitis. Colonic neoplasia has not been found in juvenile rhesus macaques with chronic colitis.

Colitis has also been described in cotton-top tamarins (Sanguinus oedipus) and other Callitrichidae (Chalifoux et al. 1982; Lushbaugh et al. 1985). Cotton-top tamarins have been investigated as a model for inflammatory bowel disease because of the high incidence of colonic neoplasia that develops in association with colitis (Chalifoux and Bronson 1981; Chalifoux et al. 1985). Prevalent colonic lesions in this species include crypt abscesses, decreased numbers of goblet cells, atypia of surface epithelium, and infiltration of lamina propria with neutrophils. The extent of mono- 
nuclear cell infiltration is variable (Chalifoux et al. 1982), and the chronic nature of these lesions has been considered "equivocal" (Madara et al. 1985). Increased numbers of mononuclear cells in the lamina propria are observed in some cases, but, in contrast to juvenile rhesus macaques with chronic colitis and humans with inflammatory bowel disease, plasma cells and macrophages are sparse (Chalifoux et al. 1982). Spontaneous and experimentally induced examples of chronic intestinal inflammation have also been described in a variety of nonprimate mammalian species (Pfeiffer 1985).

Acknowledgements. The authors are grateful to Drs. John Anderson and Elizabeth Ford for their insight and experience in nonhuman primate medicine. This research was supported by United States Public Health Service grant RR00167 from the Division of Research Resources, National Institutes of Health.

\section{References}

Ackerman JI, Newcomer CE, Fox JG (1982) Intestinal carriage of Campylobacter fetus subsp. jejuni in laboratory animals (abstract no 118). Lab Anim Sci 32:442

Adler R, Hendricks A, Rush J, Fondacaro JD (1990) Chronic colitis of juvenile rhesus macaques: mucosal tissue levels of interleukin-1 (IL-1) and leukotriene B-4 (LTB-4). Gastroenterology 98:A436

Baskin GB, Murphey-Corb M, Watson EA, Martin LN (1988) Necropsy findings in rhesus monkeys experimentally infected with cultured simian immunodeficiency virus (SIV)/delta. Vet Pathol 25:456-467

Burrows RB (1972) Protozoa of the intestinal tract. In: Fiennes RN (ed) Pathology of simian primates, part II: infectious and parasitic diseases. Karger, Basel, pp 2-56

Chalifoux LV, Bronson RT (1981) Colonic adenocarcinoma associated with chronic colitis in cotton-top marmosets, Sanguinus oedipus. Gastroenterology 80:942-946

Chalifoux LV, Bronson RT, Escajadillo A, McKenna S (1982) An analysis of the association of gastroenteric lesions with chronic wasting syndrome of marmosets. Vet Pathol 19 [Suppl 7]:141-162

Chalifoux LV, Hunt RD, King NW Jr (1985) Adenocarcinoma of the colon and chronic colitis in Sanguinus oedipus: a possible model for analogous human disease. In: Pfeiffer CJ (ed) Animal models of intestinal disease. CRC Press, Boca Raton, pp 69-78

Dayal Y, DeLellis RA (1989) The gastrointestinal tract. In: Cotran RS, Kumar V, Robbins SL (eds) Pathologic basis of disease, 4 th edn. Saunders, Philadelphia, pp 827-909

Dyson JL (1975) Herniation of mucosal epithelium into the submucosa in chronic ulcerative colitis. J Clin Pathol 28:189-194

Fox JG (1982) Campylobacteriosis: a new disease in laboratory animals. Lab Anim Sci 32:625-637

Glickman RM (1987) Inflammatory bowel disease. In: Braunwald $\mathrm{E}$, Isselbacher $\mathrm{KJ}$, Petersdorf RG, Wilson
JD, Martin JB, Fauci AS (eds) Harrison's principles of internal medicine, 11th edn. McGraw-Hill, New York, pp $1277-1290$

Kumar NB, Nostrant TT, Appelman HD (1982) The histopathologic spectrum of acute self-limited colitis (acute infectious-type colitis). Am J Surg Pathol 6:523-529

Lackner AA, Moore PF, Marx PA, Munn RJ, Gardner MB, Lowenstine LJ (1990) Immunohistochemical localization of type $D$ retrovirus serotype 1 in the digestive tract of rhesus monkeys with simian AIDS. J Med Primatol 19:339-349

Lauritsen K, Laursen LS, Bukhave K, Rask-Madsen J (1985) Effects of systemic prednisolone on arachadonic acid metabolites determined by equilibrium in vivo dialysis of rectum in severe relapsing ulcerative colitis (abstract). Gastroenterology 88:A1466

Ligumsky M, Simon PL, Karmeli F, Rachmilewitz D (1988) Interleukin-1: possible mediator of the inflammatory response in ulcerative colitis (UC) (abstract). Gastroenterology 94:A263

Lushbaugh C, Humason G, Clapp N (1985) Histology of colitis: Sanguinus oedipus oedipus and other marmosets. Dig Dis Sci 30 [12 Suppl]:45S-51S

MacDermott RP, Stenson WF (1988) Alterations of the immune system in ulcerative colitis and Crohn's disease. Adv Immunol 42:285-328

Madara JL, Podolsky DK, King NW, Sehgal PK, Moore R, Winter HS (1985) Characterization of spontaneous colitis in cotton-top tamarins (Sanguinus oedipus oedipus) and its response to sulfasalazine. Gastroenterology 88:13-19

Matsumoto T, Nagura H, Kitano A, Hashimura H, Hiki M, Okawa K, Kobayashi K (1988) Immunocytochemical demonstration of activated lymphokine cascade in the colonic mucosa in patients with ulcerative colitis (abstract). Gastroenterology 94:A290

Nostrant TT, Kumar NB, Appelman HD (1987) Histopathology differentiates acute self-limited colitis from ulcerative colitis. Gastroenterology 92:318-328

Pfeiffer CJ (ed) (1985) Animal models for intestinal disease. CRC Press, Boca Raton

Russell RG, Rosenkranz SL, Lee LA, Howard H, DiGiacomo RF, Bronsdon MA, Blakley GA, Tsai C-C, Morton WR (1987) Epidemiology and etiology of diarrhea in colony-born Macaca nemestrina. Lab Anim Sci 37:309-316

Shadduck JA, Pakes SP (1978) Protozoal and metazoal diseases. In: Benirschke K, Garner FM, Jones TC (eds) Pathology of laboratory animals, vol II. Springer, Berlin Heidelberg New York, pp 1587-1696

Sharon P, Stenson WF (1984) Enhanced synthesis of leukotriene $\mathrm{B} 4$ by colonic mucosa in inflammatory bowel disease. Gastroenterology 86:453-460

Sharon P, Ligumsky M, Rachmilewitz D, Zor U (1978) Role of prostaglandins in ulcerative colitis. Enhanced production during active disease and inhibition by sulfasalazine. Gastroenterology 75:638-640

Shorter RG, Kirsner JB (1985) Immunology of idiopathic inflammatory bowel disease. In: Shorter RG, Kirsner JB (eds) Gastrointestinal immunity for the clinician. Grune and Stratton, Orlando, pp 171-187

Smalley JR, Klish WJ, Brown MR, Campbell MA (1982) Chronic diarrhea associated with Campylobacter. Clin Pediatr (Phila) 21:220

Stenson WF (1986) Role of lipoxygenase products as mediators of inflammation in IBD. In: Rachmilewitz D (ed) Inflammatory bowel diseases. Nijhoff, The Hague, pp 95-103 
Toft JD II (1982) The pathoparasitology of the alimentary tract and pancreas of nonhuman primates: a review. Vet Pathol 19 [Suppl 7]:44-92

Vilaseca J, Salas A, Guarner F, Rodriguez R, Malagaleda JR (1990) Participation of thromboxane and other eico- sanoid synthesis in the course of experimental inflammatory colitis. Gastroenterology 98:269-277

Walker RI, Caldwell MB, Lee EC, Guerry P, Trust TJ, Ruiz-Palacios GM (1986) Pathophysiology of Campylobacter enteritis. Microbiol Rev 50:81-94

\title{
Adenocarcinoma, Colon, Cotton-Top Tamarin
}

\author{
Laura V. Chalifoux, Norval W. King, Jr., and Lorna D. Johnson
}

Synonyms. Colonic adenocarcinoma; carcinoma of colon

\section{Gross Appearance}

Early noninvasive colonic adenocarcinoma in the tamarin may not be visible grossly or may be indistinguishable from the lesions of chronic active colitis, with which it occurs. Occasionally a small, white mucosal plaque or ulcer may be seen. In more advanced invasive cases there is desmoplasia with thickening of the wall, constriction of the lumen and occasional adhesions to adjacent viscera. Dilatation of the colon may be present proximal to fibrotic constrictions. Colonic, ileocolic and peripancreatic lymph nodes are often enlarged, white and firm. Foci of adenocarcinoma are often multiple and may occur at any site in the cecum, colon and rectum; the most common sites are the colorectal junction and the proximal colon near the ileum. Polyps are not seen. Perforation of the colon wall due to invasion of neoplastic cells may result in peritonitis and septicemia.

\section{Microscopic Features}

The early adenocarcinoma arises in the bases of crypts (Figs. 94, 95), usually within crypts which are distorted due to chronic colitis. Neoplasms may occur within the inflamed mucosa or at sites in a quiescent stage of colitis. The intramucosal foci, often multiple, spread laterally in the mucosa, never forming polypoid masses. The patterns of growth are varied and consist of small groups of somewhat pleomorphic cells arranged in sheets (Figs. 96, 97), poorly formed glands (Figs. 98, 99), or cords. Occasionally, single cells may be isolated. The cells are sometimes large
(Fig. 100) with pale pink cytoplasm which stains diffusely positive with periodic acid-Schiff (PAS). Signet ring cells containing PAS positive mucin may also be present in large numbers. Inflammatory leukocytes are frequent at primary sites and usually accompany the metastatic tumor cells. Necrosis and ulceration of the overlying mucosa may occur (Fig. 101).

Primary foci of adenocarcinoma may be observed in the mucosa prior to the invasion of deeper structures. Once invasive, the tumors are very aggressive, forming poorly differentiated glands and pools of sequestered mucin throughout the layers of the colon wall (Fig. 102), usually accompanied by desmoplasia. The invasive and metastatic cells tend to produce more mucin than do the intramucosal adenocarcinoma cells. Clumps of the neoplastic cells may be present in lymphatics and in the subcapsular sinuses of lymph nodes, including colonic, ileocolic and peripancreatic lymph nodes. These metastatic adenocarcinomas replace the nodal architecture with sheets of cells (Fig. 103), which may include fairly well differentiated crypts (Fig. 104) or large pools of mucin with poorly discernible cells within them (Fig. 105). Curiously, inflammation similar to that seen in the mucosa often accompanies the lymph node metastases and crypt abscesses may be seen. Metastases to the lung (Fig. 106), spleen and liver are infrequent.

\section{Ultrastructure}

Intracytoplasmic cysts lined by a cell membrane which bears intestinal microvilli have been described in neoplastic colonic cells of tamarins (Lushbaugh et al. 1978). The cyst may contain PAS positive inclusions, fluid, or stainable material and minute vesicles resembling those of an intes- 